\title{
The Recombinant Luciferase of the Fungus Neonothopanus nambi: Obtaining and Properties
}

\author{
A. Yu. Gorokhovatsky ${ }^{a}$, T. V. Chepurnykh ${ }^{a}$, A. S. Shcheglov ${ }^{a}$, Yu. A. Mokrushina ${ }^{a}$, M. N. Baranova ${ }^{a}$, \\ S. A. Goncharuk ${ }^{a}$, K. V. Purtov ${ }^{b, *}$, V. N. Petushkov ${ }^{b}$, N. S. Rodionova ${ }^{b}$, and I. V. Yampolsky ${ }^{a}$ \\ Presented by Academician J.I. Gitelson
}

Received October 15, 2020; revised October 27, 2020; accepted October 29, 2020

\begin{abstract}
A key component of the recently described bioluminescent system of higher fungi is luciferase, a new class of proteins. The properties of fungal luciferase and their relationship with its structure are interesting both for improving autoluminescent systems already created on its basis and for creating new ones. Therefore, it is extremely important to understand the spatial structure of this protein. We have performed heterologous expression and purification of Neonothopanus nambi luciferase, obtained a protein suitable for subsequent crystallization, and also determined some biochemical properties of the recombinant luciferase.
\end{abstract}

Keywords: bioluminescence, luciferase, nnLuz, Neonothopanus nambi, heterologous expression, Pichia pastoris

DOI: $10.1134 / \mathrm{S} 1607672921010051$

Bioluminescent systems are widely used both for research purposes and for drug development and diagnostics [1-6]. The recently clarified bioluminescent system of fungi is a promising tool for biomedical research [7]. On its basis, autonomously luminescing yeast [8] and plants [9] have already been created. However, the key component of this system, luciferase (nnLuz), remains poorly understood. The lack of homology with other enzymes does not allow modeling the spatial structure of this protein, and the difficulty of its isolation from a natural source prevents obtaining a sufficient amount of this protein for crystallization and characterization of its properties. Thus, obtaining recombinant $N$. nambi luciferase is currently a relevant task.

At the first stage of the study, we compared the luciferase activity of $N$. nambi expressed in three standard systems: E. coli, yeast Pichia pastoris, and HEK293T human cell line. The yeast $P$. pastoris demonstrated the maximum luminescence in response to the addition of fungal luciferin. Therefore, for further experiments, we decided to use the yeast strain, producing luciferase with a sequence of six histidine resi-

\footnotetext{
${ }^{a}$ Shemyakin-Ovchinnikov Institute of Bioorganic Chemistry, Russian Academy of Sciences, Moscow, Russia

${ }^{b}$ Institute of Biophysics, Federal Research Center

"Krasnoyarsk Scientific Center of the Siberian Branch of the Russian Academy of Sciences", Krasnoyarsk, Russia

*e-mail:purtovk@mail.ru
}

dues at the C-terminus of the protein. Yeast was cultured according to the standard procedure using the GS115 strain [10].

Yeast biomass was lysed in $100 \mathrm{mM}$ Na-phosphate buffer (pH 7.0) containing $100 \mathrm{mM} \mathrm{NaCl}, 5 \mathrm{mM}$ EDTA, $10 \mathrm{mM}$ 2-mercaptoethanol, and $1 \mathrm{mM}$ PMSF in a high-pressure homogenizer (600 bar, IKA HPH). The lysate was centrifuged $(8000 \mathrm{~g}, 30 \mathrm{~min})$ at $4^{\circ} \mathrm{C}$ and the membrane fraction containing luciferase was pelleted by ultracentrifugation $(150000 \mathrm{~g}, 90 \mathrm{~min})$ at $4^{\circ} \mathrm{C}$. To select the conditions for luciferase solubilization, the membranes were suspended in $50 \mathrm{mM}$ HEPES-Na buffer ( $\mathrm{pH} 8.0$ ) containing $500 \mathrm{mM} \mathrm{NaCl}, 20 \%$ glycerol (buffer A), and various detergents at $4^{\circ} \mathrm{C}$ overnight (Fig. 1). Almost all of the detergents showed approximately the same ability to extract luciferase, except for the detergent OG (octyl glycoside). For preparative extraction, we used DDM at a concentration of $10 \mathrm{mM}$, due to its availability and good applicability for chromatography with UV detection. All chromatographic experiments were performed in the cold. The detergent-solubilized membrane fraction was loaded onto a column packed with the TALON sorbent for metal affinity chromatography equilibrated with buffer A with $0.02 \%$ DDM, and the column was washed with the same buffer. Then, the column was washed with $20 \mathrm{mM}$ MES-Na, $0.5 \mathrm{M} \mathrm{NaCl}$, and $10 \%$ glycerol buffer (pH 6.2, buffer B) containing 0.02\% DDM. Adsorbed luciferase was eluted with buffer B containing $0.1 \% \mathrm{DDM}$ and $200 \mathrm{mM}$ imidazole. The fractions with the highest luminescence activity were loaded 


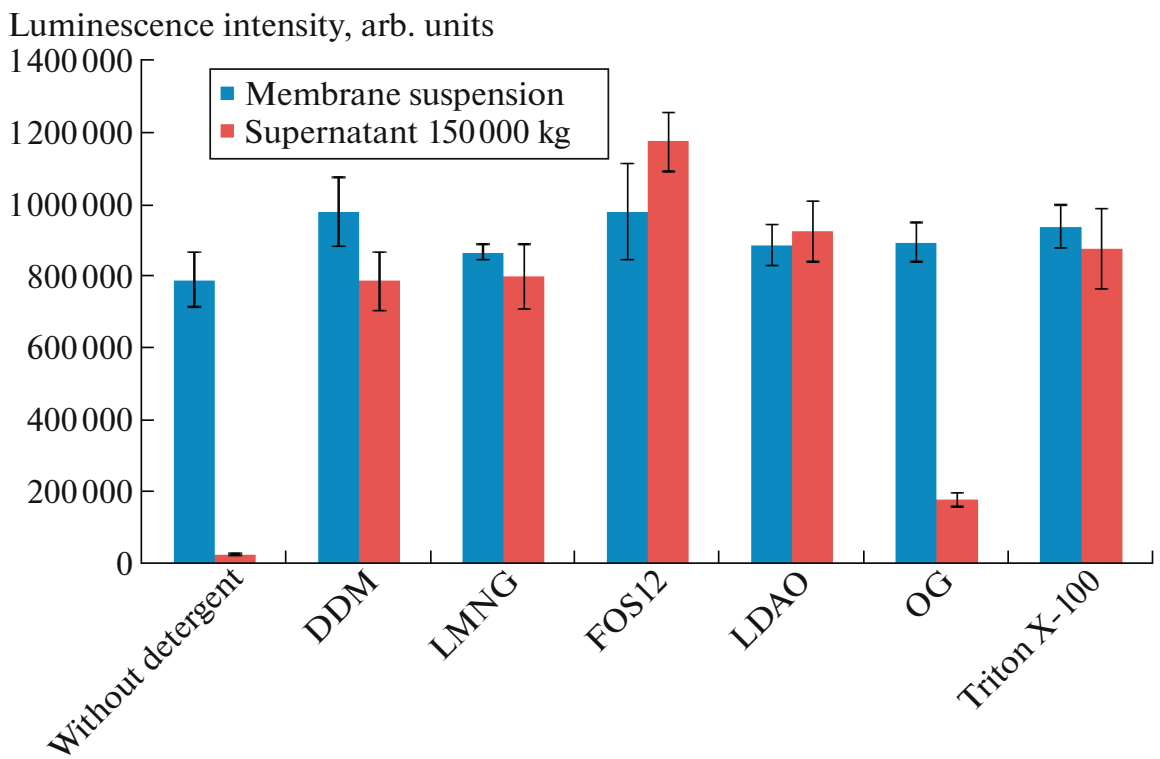

Fig. 1. Solubilization of nnLuz luciferase from P. pastoris membranes suspended in buffer (see text) with addition of various detergents at a concentration of $10 \mathrm{mM}\left(100 \mathrm{mM}\right.$ for OG) for $16 \mathrm{~h}$ at $4^{\circ} \mathrm{C}$. After centrifugation $(150000 \mathrm{~g}, 90 \mathrm{~min})$ at $4^{\circ} \mathrm{C}$, the bioluminescence activity of luciferase in the supernatant was measured in $200 \mathrm{mM} \mathrm{Na}$-phosphate buffer (pH 8.0) containing $500 \mathrm{mM} \mathrm{Na}_{2} \mathrm{SO}_{4}$, $0.1 \% \mathrm{DDM}$, and $50 \mu \mathrm{M}$ fungal luciferin. Data are represented as the mean value \pm standard deviation.

onto a column with Sephacryl S-300 in $50 \mathrm{mM} \mathrm{Na-}$ phosphate buffer ( $\mathrm{pH} 7.0)$ containing $150 \mathrm{mM} \mathrm{NaCl}$ and $0.04 \%$ DDM for gel filtration. As a result, a recombinant $N$. nambi luciferase with a purity of more than $95 \%$ (Fig. 2) and a yield of $10 \mathrm{mg}$ per liter of $P$. pastoris culture was obtained.

During gel filtration on a Superdex 200 column in the presence of DDM detergent micelles, luciferase is eluted as a single peak corresponding to a molecular weight of about $60 \mathrm{kDa}$. On the one hand, luciferase can be a dimer, because the calculated monomer mass determined from the amino acid sequence is $31.4 \mathrm{kDa}$. However, given the size of the DDM micelle (40$70 \mathrm{kDa}$ ) and gel filtration conditions, luciferase is more likely to be a detergent-bound monomer, although the exact stoichiometry of this complex remains unknown.

The luciferase preparation obtained by gel filtration was studied by circular dichroism spectroscopy. The spectrum was recorded in $20 \mathrm{mM}$ Na-phosphate buffer containing $100 \mathrm{mM} \mathrm{NaCl}$ and $0.04 \%$ DDM (pH 7.4) at $5^{\circ} \mathrm{C}$ on a $\mathrm{J}-810$ spectropolarimeter (JASCO, Japan) at a protein concentration of $11 \mu \mathrm{M}$ in a cell $0.01 \mathrm{~cm}$ thick. Data were processed using the CONTINLL software (CDPro package) and a set of reference spectra (SMP56). The results of the analysis of the obtained spectrum are presented in Table 1 . The presence of beta-structures and alpha-helical regions presented in Table 1 indicates that the purified luciferase preparation with a high probability contains the protein with the native structure.

Luciferase activity in vitro strongly depends on the presence of detergents in the medium (Fig. 3). We compared the bioluminescence activity of the recombinant nnLuz in the presence of Tween-20, Triton X-100, NP-40, digitonin, DDM, FOS-12, and CHAPS. Different detergents contribute to the luminescence reaction to varying degrees. The highest luciferase activity was observed in the presence of FOS-12 ( $n$-dodecylphosphocholine). However, we showed that, during storage in the presence of the detergent FOS-12, the purified nnLuz lost its activity, whereas during storage in the presence of DDM, no loss of luciferase activity was observed. Therefore, the purification and measurement of luciferase activity was also performed in the presence of DDM in order to prevent the formation of mixed micelles during measurements.

The optimum $\mathrm{pH}$ for the bioluminescence reaction is 8.0 (Fig. 4a). The recombinant luciferase is a temperature-sensitive enzyme: incubation at $30^{\circ} \mathrm{C}$ for $10 \mathrm{~min}$ almost completely inactivated the enzyme (Fig. 4b).

Table 1. Analysis of the obtained circular dichroism spectrum

\begin{tabular}{c|c|c|c|c|c}
\hline Number of aa & Alpha-helix, $\%$ & Beta structure, $\%$ & Turn, $\%$ & Unordered, $\%$ & NRMSD \\
\hline 275 & 21.5 & 26.8 & 22.5 & 29.1 & 0.05 \\
\hline
\end{tabular}




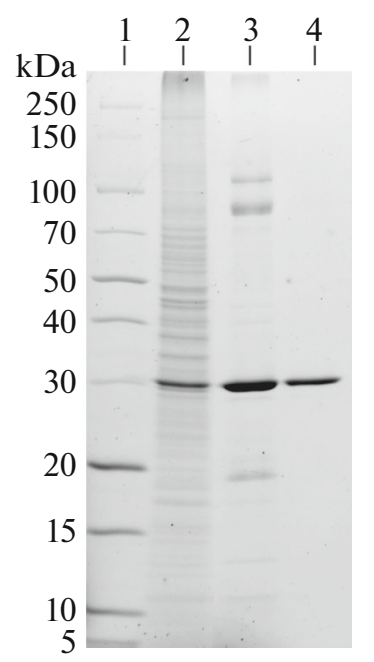

Fig. 2. Electrophoresis under denaturing conditions of fractions during isolation of the recombinant $N$. nambi luciferase. Designations: 1-molecular weight markers; 2-membrane fraction of P. pastoris cells; 3 -fraction containing the recombinant $N$. nambi luciferase after metal chelate chromatography; 4-fraction containing the recombinant $N$. nambi luciferase after gel filtration chromatography. The gel was stained with Coomassie Brilliant Blue G250.

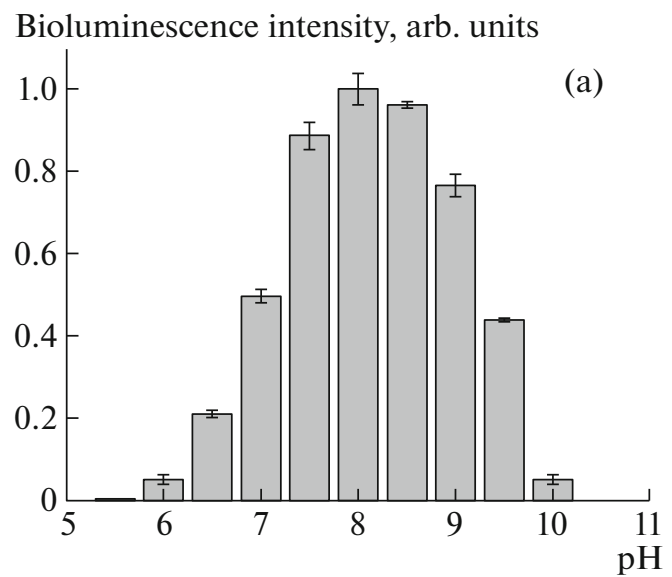

Bioluminescence intensity, arb. units 6000000 -

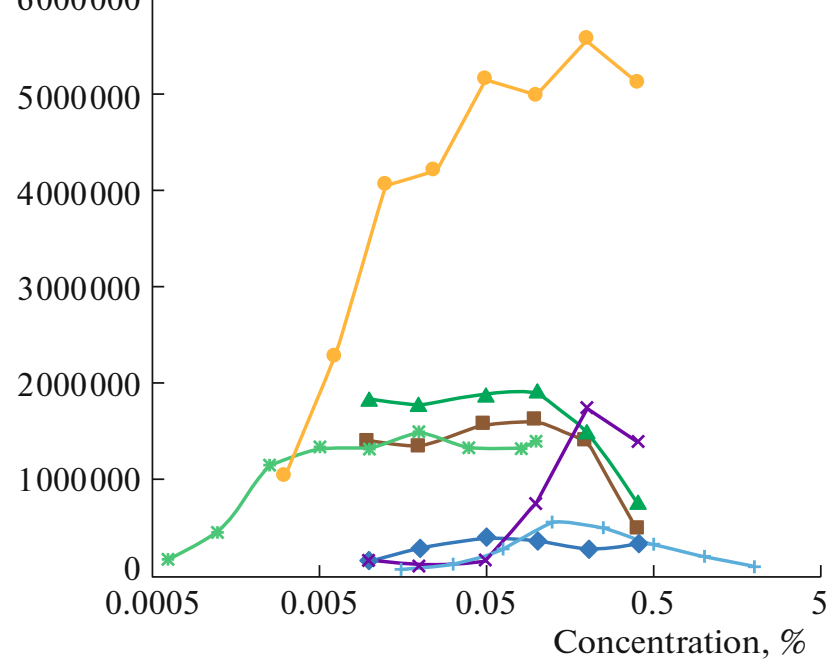

$$
\begin{array}{ll}
\multimap \text { Tween } 20 & - \text { DDM } \\
\rightarrow-\text { Triton X } 100 \text { red } & - \text { FOS-12 } \\
- \text { NP } 40 & \div \text { CHAPS } \\
\rightarrow \text { Digitonin } &
\end{array}
$$

Fig. 3. Effect of detergents on luciferase bioluminescence. The reaction was performed in $200 \mathrm{mM}$ Na-phosphate buffer ( $\mathrm{pH}$ 8.0) containing the indicated concentration of the detergent and $50 \mu \mathrm{M}$ of fungal luciferin. The measurements were performed for $30 \mathrm{~s}$. The integrated light intensity values are shown.

Bioluminescence intensity, arb. units

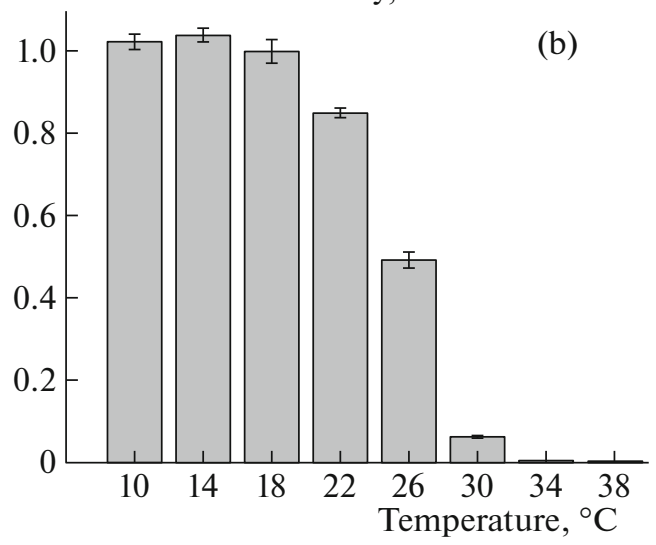

Fig. 4. pH-dependence (a) and thermal stability (b) of $N$. nambi luciferase bioluminescence. The luminescence measurement was carried out after incubation for $10 \mathrm{~min}$ at the indicated temperature in $100 \mathrm{mM} \mathrm{Na}$-phosphate buffer ( $\mathrm{pH}$ 7.0). The reaction was performed in $100 \mathrm{mM}$ buffer at the indicated $\mathrm{pH}$ containing $0.1 \%$ DDM and $50 \mu \mathrm{M}$ fungal luciferin at room temperature. The light was integrated for $60 \mathrm{~s}$. Data are represented as the mean value \pm standard deviation.

The Michaelis-Menten constant was determined for the luciferin oxidation reaction catalyzed by the recombinant $N$. nambi luciferase. The reaction was performed at a luciferase concentration of $50 \mathrm{nM}$ in $200 \mathrm{mM}$ Na-phosphate buffer (pH 8.0) containing $500 \mathrm{mM} \mathrm{Na}_{2} \mathrm{SO}_{4}$ and $0.1 \%$ DDM at room temperature; the concentration of fungal luciferin was varied from $2 \mathrm{nM}$ to $50 \mu \mathrm{M}$. The initial bioluminescence intensity values were approximated by the MichaelisMenten function using the Origin software package. $K_{\mathrm{M}}$ was $1.09 \pm 0.06 \mu \mathrm{M}$.

Thus, in this study, we obtained and characterized the recombinant $N$. nambi luciferase. The developed technique for isolating this enzyme will be further used 
to accumulate sufficient amounts of the protein for crystallization and study of the spatial structure of luciferase by NMR.

\section{FUNDING}

The work was supported by the Russian Science Foundation (project no. 16-14-00052-P). The creation of the luciferase-producing yeast strain nnLuz was supported by the President's grant for state support of the leading scientific schools of the Russian Federation (NSh-2605.2020.4).

\section{COMPLIANCE WITH ETHICAL STANDARDS}

The authors declare that they have no conflict of interest. This article does not contain any studies involving animals or human participants performed by any of the authors.

\section{OPEN ACCESS}

This article is distributed under the terms of the Creative Commons Attribution 4.0 International Public License (http://creativecommons.org/licenses/by/4.0/), which permits unrestricted use, distribution, and reproduction in any medium provided you give appropriate credit to the original author(s) and the source, provide a link to the Creative Commons license, and indicate if changes were made.

\section{REFERENCES}

1. Yan, Y., Shi, P., Song, W., and Bi, S., Chemiluminescence and bioluminescence imaging for biosensing and therapy: in vitro and in vivo perspectives, Theranostics, 2019, vol. 9, pp. 4047-4065.

https://doi.org/10.7150/thno.33228
2. Fleiss, A. and Sarkisyan, K.S., A brief review of bioluminescent systems, Curr. Genet., 2019, vol. 65, pp. 877-882. https://doi.org/10.1007/s00294-019-00951-5

3. Pomper, M.G. and Gelovani, J.G., Molecular Imaging in Oncology, CRC Press, 2008. https://doi.org/10.1102/1470-7330.2004.0060

4. Shimomura, O., Bioluminescence: Chemical Principles and Methods, Singapore: World Sci. Publ., 2006. https://doi.org/10.1142/6102

5. van Leeuwen, F.W., Hardwick, J.C., and van Erkel, A.R., Luminescence-based imaging approaches in the field of interventional molecular imaging, Radiology, 2015, vol. 276 , no. 1 , pp. $12-29$. https://doi.org/10.1148/radiol.2015132698

6. England, C.G., Ehlerding, E.B., and Cai, W., Nanoluc: a small luciferase is brightening up the field of bioluminescence, Bioconjugate Chem., 2016, vol. 27, no. 5, pp. $1175-1187$. https://doi.org/10.1021/acs.bioconjchem.6b00112

7. Yampol'skii, I.V., Osipova, Z.M., and Shcheglov, A.S., New bioluminescent system of fungi: prospects for use in medical research, Vestn. Ross. Gos. Med. Univ., 2018, vol. 1 , pp. $80-83$.

https://doi.org/10.24075/vrgmu.2018.004

8. Kotlobay, A.A., Sarkisyan, K.S., Mokrushina, Y.A., et al., Genetically encodable bioluminescent system from fungi, Proc. Natl. Acad. Sci. U. S. A., 2018, vol. 115, pp. $12728-12732$. https://doi.org/10.1073/pnas.1803615115

9. Mitiouchkina, T., Mishin, A.S., Somermeyer, L.G., et al., Plants with genetically encoded autoluminescence, Nat. Biotechnol., 2020. https://doi.org/10.1038/s41587-020-0500-9

10. Pichia Expression Kit. A Manual of Methods for Expression of Recombinant Proteins using pPICZ and PICZ-alpha in Pichia pastoris, Invitrogen ES, Catalog, 2009.

Translated by M. Batrukova 